\title{
Low birth weight and prenatal care in Colombia: a cross-sectional study
}

\author{
Ángela María Pinzón-Rondón*, Vivian Gutiérrez-Pinzon, Humberto Madriñan-Navia, Jennifer Amin, \\ Paula Aguilera-Otalvaro and Alfonso Hoyos-Martínez
}

\begin{abstract}
Background: Low birth weight (LBW) is one of the most important factors affecting child morbidity and mortality worldwide; approximately one third of neonatal deaths are attributable to it. Most research and public health policy on LBW arise from developed nations, despite that most cases (96.5\%) take place in developing countries. The specific features of prenatal care that prevent LBW in developing countries are unclear. This study aims to identify the characteristics of prenatal care associated with LBW in a developing country as Colombia.

Methods: Observational cross-sectional study using data from the Colombian Demographic and Health Survey 2010. A total of 10,692 children were included. Descriptive statistics were calculated, followed by bivariate regressions of LBW with all other study variables. Finally, stepwise logistic binomial regression analyses were done.

Results: A LBW prevalence of $8.7 \%$ was found. Quality of prenatal care $(95 \% \mathrm{Cl}: 0.33,0.92 ; \mathrm{OR}=0.55)$, number of prenatal visits ( $95 \% \mathrm{Cl}: 0.92,0.93 ; \mathrm{OR}=0.92)$, and first prenatal visits during pregnancy $(95 \% \mathrm{Cl}: 1.02,1.07 ; \mathrm{OR}=1.08)$ were associated with LBW even after controlling for all the studied variables. The health care provider conducting prenatal checkup, and insurance coverage, were not associated with LBW.

Conclusion: This research provides information on the characteristics of prenatal care (quality, number of visits, and gestational age at first prenatal visit) which may strengthen LBW prevention in Colombia and possibly in countries with similar socioeconomic characteristics.
\end{abstract}

Keywords: Low birth weight, Prenatal care, Social conditions, Colombia, Child health

\section{Background}

More than 20 million infants worldwide are born each year with low birth weight (LBW); this is an alarming number since it represents approximately 15.5 percent of all live born infants [1]. The World Health Organization (WHO) has defined this condition as the weight of live born infants of less than 2,500 grams, regardless of gestational age or any other etiology [2]. LBW is the result of either premature delivery or intrauterine growth restriction (IUGR), which are both influenced by genetic background, environmental exposure, behavioral patterns and access to health care [3].

One of the United Nations Millennium Development Goals (MDG) for 2015, seeks to reduce the under-five child mortality rate by $2 / 3$ [4]. LBW has been recognized

\footnotetext{
* Correspondence: angela.pinzon@urosario.edu.co

Escuela de medicina y ciencias de la salud, Universidad del Rosario, Bogota,
} Colombia

as one of the most important factors affecting child morbidity and mortality; between 28 and 30 percent of neonatal deaths are attributable to this condition [5,6]. As one of the most important predictors of child survival, LBW needs to be studied and understood in order to efficiently decrease child mortality. Moreover, since LBW has been also associated with increased morbidity later in life, [7] understanding this condition is not only relevant for early childhood but for adulthood as well.

Even though the prevalence of LBW is higher in developing countries ( $96.5 \%$ of all cases), most of the research on this topic is conducted in developed nations, [1] and the results from research conducted in industrialized nations are not necessarily applicable to less developed nations.

The under-five mortality rate in Colombia has improved during the last years, decreasing from 34 per 1000 live births in 1990, to 18 per 1000 live births in 
2012 [8]. Yet, this rate is still far from the nation's MDG target (11 per 1000 by 2015). Therefore, there is still much to do with.

Prenatal care is among the most important tools available to health care providers to detect time-sensitive, modifiable obstetric risk factors (infections, micronutrients deficiencies, metabolic and placental diseases) that may impact on optimal fetal development, and final birthweight. Even though the characteristics of an ideal prenatal care are still a matter of debate, in industrialized countries it is clear that ineffective practices are still part of the antenatal agenda [9-11]. Developing countries usually follow guidelines based on research conducted in industrialized nations. Although each developing country has its own characteristics, the importance of antenatal care in these countries seems to be underestimated; visits tend to be irregular and pregnant women do not tend to initiate prenatal care opportunely, nor do they comply with health recommendations [2]. According to Unicef, only half of all women worldwide receive an adequate prenatal care, and most of these women receiving adequate prenatal care are in the developed world [12]. Information on the characteristics of prenatal care leading to satisfactory obstetric outcomes in developing countries is insufficient. This research aims to identify the characteristics of prenatal care in a developing nation, Colombia, that are associated with LBW.

\section{Methods}

A cross sectional study using data from the Colombian Demographic and Health Survey (DHS) phase-V was designed. The DHS is an international initiative that provides decisive information for policy formation and program planning. It uses nationally representative household surveys which includes data on population, nutrition and health. This data was collected from November 2009 to November 2010; respondents were selected through a multistage, stratified sampling procedure, including rural and urban areas [13].

\section{Population}

The population was children born in Colombia from November 2006 to November 2010.

\section{Inclusion and exclusion criteria}

We included all children of women, 13 to 49 years of age, who answered the Colombian DHS 2010. We excluded children without reliable information on birth weight, and children born overseas.

\section{Sample}

The initial sample used in this study was all children born from women included in the DHS survey (13 to 49 years old) within the 36 months preceding data collection. This sample included 17,443 children, and it was reduced to 17,441 when children born overseas were excluded. The sample was further limited to those whose birth weight was either registered in the birth certificate, or the mother affirmed (during data collection) to accurately recall the birth weight and she provided a valid value. The final sample was 10,692 children.

\section{Variables}

The outcome variable was LBW, defined as the weight at birth of less than 2,500 grams (birth weight $\geq 2,500 \mathrm{~g}=0$; birth weight $<2,500 \mathrm{~g}=1$ ). Birth weight was the weight of the newborn in grams at the moment of birth regardless of gestational age or any other factor that might have an influence on it. Birth weight information was gathered either from birth certificates, or from information provided by a mother who affirmed recalling the birth weight accurately and provided a valid value.

The exposure variables were the characteristics of the prenatal care. Provider: divided in three dummy variables -1) No antenatal care, 2) Physician and 3) Other health professional-. Quality of prenatal care: this variable summarizes information on the interventions that the mother received during the prenatal care: education, physical examination -weight, height, uterine height, blood pressure-, immunization -tetanus-, tests -blood and urine-, and nutritional supplements -iron and folic acid-. A factor analysis indicated that the multiple interventions represented a single concept, hence, a new scale of quality of prenatal care was created (the scale had a score from 0 to 1,0 being lowest quality and 1 being highest quality of prenatal care, alpha Cronbach 0.898 . Women with no prenatal care had a score of 0). Number of prenatal care visits, First prenatal care (month in which the prenatal care was started. For women with no prenatal care it was coded as 9), and Health insurance coverage: mother's health insurance covered prenatal care $(0=$ no; $1=$ yes $)$.

The control variables were divided in pregnancy characteristics, child characteristics, mother characteristics and context characteristics. The following pregnancy characteristics were considered: weeks of gestational age at delivery, preceding birth interval $\leq 1$ year $(0=$ yes; $1=$ no), substance abuse during pregnancy (score from 0 to 3 of the amount and type of substance abuse during pregnancy -tobacco, alcohol, marijuana, heroin and cocaine-), wanted child (regression score from a factor analysis of three variables: wanted the child, wanted the pregnancy and when did she want to become pregnant).

The child characteristics included in the analysis were sex $(0=$ male; $1=$ female $)$ and product of a multiple pregnancy $(0=$ no; $1=$ yes $)$.

The assessed mother characteristics were age (in years), education (in single years), employment (the mother is 
employed $0=$ no; $1=$ yes), marital status (divided in three dummy variables: 1) never married, 2) currently married and 3) previously married), height (in centimeters), body mass index $(B M I)$ (divided in three dummy variables: 1 ) low -less than 18.5-, 2) regular -from 18.5 to 30-, and 3) high -above 30-), total children ever born, previously terminated pregnancy $(0=$ no; $1=$ yes $)$, history of sexual abuse $(0=$ no; $1=$ yes $)$, history of physical abuse $(0=$ no; $1=$ yes $)$, history of psychological abuse $(0=$ no; $1=$ yes $)$, and final say (regression score from a factor analysis of nine variables evaluating the women's participation on household decisions).

Finally, the following context characteristics were considered: number of household members, wealth index (calculated by the DHS, with higher grades indicating greater wealth), urban residency $(0=$ no; $1=$ yes), migration (living in the city of residence for less than a year), region (divided in 6 dummy variables: 1) Atlantic, 2) Oriental, 3) Central, 4) Pacific, 5) Bogota and 6) National Territories), household head (divided in three dummy variables: 1) woman, 2) partner and 3) other), and sanitation (score of clean water supply and healthy indoor environment).

\section{Statistical analysis}

Analysis of data was done using the IBM Statistical Package for the Social Sciences version 20 (IBM SPSS 20.0). A cut off $P$ value of $<0.05$ was considered of statistical significance. First, descriptive statistics of all study variables were calculated -proportions for categorical variables, and mean, standard deviation, minimum and maximum for numerical variables-. Second, bivariate regressions of all study variables with LBW were obtained using chi square for categorical variables and independent sample t-test for numerical variables. Third, a stepwise binomial logistic regression of LBW on prenatal characteristics was conducted adjusting by child, mother and context characteristics. Bogota was excluded of the analysis for its collinearity with urban residence. Finally, a sensitivity analysis was conducted considering the missing values of low birthweight as low birthweight children and then considering the missing values as normal birthweight children.

\section{Ethical consideration}

The study was conducted using secondary sources. No identifying information was available to the researchers, nor informed consent was needed. It was approved by Universidad Del Rosario School of Medicine and Health Sciences, Ethics in Research Committee.

\section{Results}

\section{Descriptive statistics}

The final sample included 10,692 Colombian children. The descriptive statistics and bivariate analysis of the studied variables are shown in Table 1 , for the total population, the normal birth weight population and the low birth weight population.

A LBW prevalence of 8.7 percent was found. In the total studied population, only a small percentage of women did not attend prenatal care (2.41\%). Among normal birth weight $(2.26 \%)$ and LBW (3.68\%) did not attend prenatal care. On the other hand, among those who received prenatal care the vast majority received prenatal care from physicians (92.95\%). The average quality of prenatal care provided was very high $(0.90$ in a scale from 0 to 1 ; in which 1 is the highest quality $\mathrm{SD}=0.17$ ). Women attended on average $6.72 \pm 2.81$ prenatal visits, with a mean gestational age for the first prenatal visit of 2.5 months \pm 1.54 , and most women had health insurance coverage (88.10\%). Deliveries occurred on average at 38.82 weeks of pregnancy \pm 1.99 , a very small percentage of women had a previous pregnancy less than 1 year before $(0.27 \%)$, and the substance abuse was uncommon. Multiple pregnancies occurred in less than 1 percent of the cases $(0.78 \%)$, and 48.14 percent of the women delivered female newborns. The mean maternal age at time of delivery was 27.57 years \pm 6.87 , mothers had on average 9.17 years of education \pm 3.77 , around half of the mothers were employed (48.23\%), and most of them were currently married (73.73\%). The average mothers' height was $156 \mathrm{~cm} \pm 58.83$, meanwhile, percentages of low, normal and high BMI were 9.2, 73.93 and 22.49 percent, respectively. In terms of abuse, approximately half (48.13\%) of the mothers reported being victims of psychological abuse, close to one in five of them had been victims of physical (17.87\%) or sexual abuse (19.09\%), and $22.49 \%$ had had an abortion.

A statistically significant difference on the absence of prenatal care between LBW infants (3.68\%) and normal birth weight infants (2.26\%), was found. On prenatal care characteristics: a physician provider was most commonly found for the group of normal birth weight (93.74\%), as compared to the group of LBW, quality of prenatal care was higher for the group of normal birth weight ( 0.90 vs. 0.87$)$, as well as number of antenatal care visits (6.12 vs. 6.79).Mothers with normal weight newborns were more likely to have health insurance coverage for antenatal care and delivery ( $88 \%$ vs. $85 \%$ ). Time of first prenatal visit was not associated with LBW.

In terms of pregnancy characteristics: as expected, LBW newborns were product of pregnancies with lower gestational age (36 weeks vs. 39 weeks). Infants with LBW were more likely to be the outcome of pregnancies with shorter interval of time between pregnancies $(0.60 \%$ vs. $0.23 \%)$, and these infants were less likely to be wanted, as compared with those infants who had a normal birth weight.

With regard to child characteristics: pregnancies resulting in LBW were more likely to have a female 
Table 1 Descriptive statistics and bivariate regressions of studied variables by birthweight

\begin{tabular}{|c|c|c|c|c|c|c|}
\hline Variables & Min & Max & $\begin{array}{l}\text { Total population } \\
n=10,692\end{array}$ & $\begin{array}{l}\text { Normal birth weight } \\
n=9,523\end{array}$ & $\begin{array}{l}\text { Low birth weight } \\
n=1,169\end{array}$ & P Value \\
\hline Low birth weight & 0 & 1 & $10.93 \%$ & & & \\
\hline \multicolumn{7}{|l|}{ Prenatal care } \\
\hline \multicolumn{7}{|l|}{ Provider } \\
\hline No antenatal care & 0 & 1 & $2.41 \%$ & $2.26 \%$ & $3.68 \%$ & 0.003 \\
\hline Physician & 0 & 1 & $92.95 \%$ & $93.74 \%$ & $91.96 \%$ & 0.020 \\
\hline Other & 0 & 1 & $4.64 \%$ & $4.00 \%$ & $4.36 \%$ & 0.634 \\
\hline Quality of prenatal care & 0 & 1 & $M=0.90 S D=0.17$ & $M=0.90 S D=0.17$ & $M=0.87 S D=0.20$ & $<0.001$ \\
\hline Number of prenatal care visits & 0 & 20 & $M=6.72 S D=2.81$ & $M=6.79 S D=2.77$ & $M=6.12 S D=3.08$ & $<0.001$ \\
\hline Gestational age at first prenatal care & 0 & 9 & $M=2.47 \mathrm{SD}=1.54$ & $M=2.46 S D=1.50$ & $M=2.53 \mathrm{SD}=1.52$ & 0.144 \\
\hline Health insurance coverage & 0 & 1 & $88.10 \%$ & $88.45 \%$ & $85.29 \%$ & 0.002 \\
\hline \multicolumn{7}{|l|}{ Pregnancy characteristics } \\
\hline Gestational age at delivery & 20 & 40 & $M=38.82 S D=1.99$ & $M=39.08 S D=1.50$ & $M=36.62 S D=3.48$ & $<0.001$ \\
\hline Preceding birth interval $\leq 1$ year & 0 & 1 & $0.27 \%$ & $0.23 \%$ & $0.60 \%$ & 0.023 \\
\hline Substance abuse & 0 & 4 & $M=0.11 S D=0.40$ & $M=0.10 S D=0.40$ & $M=0.10 S D=0.34$ & 0.541 \\
\hline Wanted child & -2 & 9 & $M=0.00 S D=1.00$ & $M=0.00 S D=1.00$ & $M=-0.05 S D=0.97$ & 0.049 \\
\hline \multicolumn{7}{|l|}{ Child characteristics } \\
\hline Product of a Multiple pregnancy & 0 & 1 & $0.78 \%$ & $0.32 \%$ & $4.53 \%$ & $<0.001$ \\
\hline Sex & 0 & 1 & $48.14 \%$ & $47.44 \%$ & $53.81 \%$ & $<0.001$ \\
\hline \multicolumn{7}{|l|}{ Mother characteristics } \\
\hline Age (years) & 13 & 49 & $M=27.57 S D=6.87$ & $M=27.6 S D=6.8$ & $M=27.34 S D=7.21$ & 0.231 \\
\hline Education & 0 & 23 & $M=9.17 \mathrm{SD}=3.77$ & $M=9.19 S D=3.70$ & $M=9.00 S D=3.70$ & 0.095 \\
\hline Employment & 0 & 1 & $48.23 \%$ & $48.26 \%$ & $47.99 \%$ & 0.860 \\
\hline \multicolumn{7}{|l|}{ Marital Status } \\
\hline Never married & 0 & 1 & $11.39 \%$ & $11.18 \%$ & $13.09 \%$ & 0.053 \\
\hline Currently married & 0 & 1 & $73.73 \%$ & $73.91 \%$ & $72.28 \%$ & 0.235 \\
\hline Previously married & 0 & 1 & $14.88 \%$ & $14.91 \%$ & $14.63 \%$ & 0.797 \\
\hline Height $(\mathrm{cm})$ & 1066 & 1835 & $M=1556.82 S D=58.83$ & $M=1558.27 \mathrm{SD}=58.68$ & $M=1544.91 S D=59.48$ & $<0.001$ \\
\hline \multicolumn{7}{|l|}{ BMl } \\
\hline Low & 0 & 1 & $9.20 \%$ & $8.76 \%$ & $12.83 \%$ & $<0.001$ \\
\hline Regular & 0 & 1 & $73.93 \%$ & $74.20 \%$ & $71.77 \%$ & 0.074 \\
\hline High & 0 & 1 & $16.91 \%$ & $17.10 \%$ & $15.40 \%$ & 0.144 \\
\hline Total children ever born & 1 & 14 & $M=2.19 S D=1.49$ & $M=2.19 S D=1.51$ & $M=2.16 S D=1.51$ & 0.425 \\
\hline Previously terminated pregnancy & 0 & 1 & $22.46 \%$ & $22.46 \%$ & $22.41 \%$ & 0.970 \\
\hline History of sexual abuse & 0 & 1 & $19.09 \%$ & $18.75 \%$ & $21.81 \%$ & 0.012 \\
\hline History of psychological abuse & 0 & 1 & $48.13 \%$ & $47.83 \%$ & $50.56 \%$ & 0.078 \\
\hline History of physical abuse & 0 & 1 & $17.87 \%$ & $17.91 \%$ & $17.54 \%$ & 0.750 \\
\hline Final say & 0 & 4 & $M=0.00 S D=1.00$ & $M=0.00 S D=1.00$ & $M=0.03 S D=1.03$ & 0.269 \\
\hline \multicolumn{7}{|l|}{ Context characteristics } \\
\hline Number of household members & 1 & 19 & $M=5.25 S D=2.23$ & $M=5.24 S D=2.28$ & $M=5.34 S D=2.33$ & 0.156 \\
\hline Wealth index & 1 & 5 & $M=2.54 \mathrm{SD}=1.27$ & $M=2.54 \mathrm{SD}=1.37$ & $M=2.49 S D=1.27$ & 0.192 \\
\hline \multicolumn{7}{|l|}{ Region } \\
\hline Atlantic & 0 & 1 & $19.67 \%$ & $19.61 \%$ & $20.19 \%$ & 0.636 \\
\hline Oriental & 0 & 1 & $16.98 \%$ & $17.14 \%$ & $15.65 \%$ & 0.202 \\
\hline
\end{tabular}


Table 1 Descriptive statistics and bivariate regressions of studied variables by birthweight (Continued)

\begin{tabular}{|c|c|c|c|c|c|c|}
\hline Central & 0 & 1 & $23.34 \%$ & $23.71 \%$ & $20.36 \%$ & 0.011 \\
\hline Pacific & 0 & 1 & $12.42 \%$ & $12.28 \%$ & $13.60 \%$ & 0.195 \\
\hline Bogota & 0 & 1 & $7.23 \%$ & $6.93 \%$ & $9.67 \%$ & 0.001 \\
\hline National territories & 0 & 1 & $20.36 \%$ & $20.34 \%$ & $20.53 \%$ & 0.879 \\
\hline Urban residency & 0 & 1 & $71.56 \%$ & $71.66 \%$ & $70.74 \%$ & 0.513 \\
\hline Migration & 0 & 1 & $12.03 \%$ & 11.91 & $13.55 \%$ & 0.047 \\
\hline \multicolumn{7}{|l|}{ Household head } \\
\hline Woman & 0 & 1 & $13.81 \%$ & $13.67 \%$ & $14.97 \%$ & 0.225 \\
\hline Partner & 0 & 1 & $53.79 \%$ & $54.27 \%$ & $49.87 \%$ & 0.004 \\
\hline Other & 0 & 1 & $32.40 \%$ & $32.06 \%$ & $35.16 \%$ & 0.033 \\
\hline Sanitation & 0 & 2 & $M=1.04 S D=0.46$ & $M=1.03 S D=0.47$ & $M=1.04 S D=0.48$ & 0.891 \\
\hline
\end{tabular}

newborn (53.81\% vs. $47.44 \%)$ and to be a multiple pregnancy $(4.53 \%$ vs. $0.32 \%)$.

Mothers of LBW infants were more likely to be of a shorter height, have a low BMI and report a history of sexual abuse (not necessarily resulting on the studied child's pregnancy).

Finally, regarding context characteristics, mothers living in the Central region (mostly rural area) were less likely to have children with LBW, while mothers living in Bogota (Colombia's capital and most densely populated city) were more likely to have a LBW infant. Additionally, households headed by the woman's partner were less likely to have babies with LBW.

\section{Multivariate regressions}

The results of the binomial logistic regressions of LBW on prenatal care variables are presented in Table 2; model 1 unadjusted and model 2 adjusted for all the study variables. After adjusting for all the study variables; the absence of prenatal care $(\mathrm{OR}=2.20)$, the quality $(\mathrm{OR}=0.55)$ and quantity $(\mathrm{OR}=0.93)$ of it, as well as the gestational age at first prenatal care visit $(\mathrm{OR}=1.08)$, were associated with LBW.

Other associated factors were weeks of gestational age at delivery $(\mathrm{OR}=0.63)$, product of a multiple pregnancy $(\mathrm{OR}=9.72)$, sex $(\mathrm{OR}=1.40)$, maternal education $(\mathrm{OR}=0.96)$, maternal height $(\mathrm{OR}=0.95)$, maternal low $\mathrm{BMI}(\mathrm{OR}=1.65)$, as compared to a regular BMI, history of sexual abuse $(\mathrm{OR}=1.15)$ and other household head, as compared with woman's partner head $(\mathrm{OR}=1.33)$.

\section{Sensitivity analysis}

In the sensitivity analysis conducted considering the low birthweight missing values as children with low birth weight, only number of prenatal care visits lost significance, while in the sensitivity analysis considering the low birth weight missing values as children with normal birthweight, there were no changes in association.

\section{Discussion}

The prevalence found, 8.7 percent, confirms what has been reported by the Colombian National Department of Statistics (DANE) and by non-governmental organizations in the country -Asi vamos en salud-, which estimated a national LBW prevalence between 8 and 9 percent $[14,15]$.

The absence of prenatal care, as reported by the literature (ORs between 1.85 and 2.59), [2,16-18] was associated with $L B W$ in this paper $(\mathrm{OR}=2.20)$. The provider of the prenatal care was not associated with LBW; it seems there is no difference between medical doctors and other health care providers in terms of final birthweight. The literature has reported that nurses, in particular those trained on obstetric care, are efficient to provide antenatal care $[19,20]$. This study confirms these findings.

Quality of prenatal care was not associated with LBW in the unadjusted model but became the factor with greater association in the adjusted one $(\mathrm{OR}=0.55)$. When pregnancy, child, mother and context characteristics are taken into account, a complete prenatal care (education, physical examination, tests and immunizations) becomes essential to ensure a good pregnancy outcome, as reported by other authors [21].

The number of prenatal visits and the gestational age for the first antenatal visit were protective factors against LBW in both the unadjusted and adjusted models. The WHO recommends at least four prenatal visits and the first visit should take place during the first trimester [22]. This study provides evidence of the importance of an early start of prenatal care and the benefits of sufficient quantity of visits.

Finally, health insurance coverage showed association with LBW in the unadjusted models but not in the adjusted one.

Other factors that were associated with LBW are well documented in the literature; these factors are: preterm 
Table 2 Binomial logistic regressions of LBW on prenatal care variables

\begin{tabular}{|c|c|c|c|c|}
\hline Variables & OR & Sig. & OR & Sig. \\
\hline Prenatal Care characteristics & \multicolumn{2}{|c|}{ Model 1} & \multicolumn{2}{|c|}{ Model 2} \\
\hline Provider: No antenatal care & 2.941 & 0.007 & 2.198 & 0.011 \\
\hline Provider: Physician & \multicolumn{4}{|c|}{ Reference } \\
\hline Provider: Other & 1.061 & 0.696 & 1.053 & 0.756 \\
\hline Quality of prenatal care & 0.642 & 0.076 & 0.552 & 0.033 \\
\hline Number of prenatal care visits & 0.864 & $<0.001$ & 0.921 & $<0.001$ \\
\hline First prenatal care & 1.133 & $<0.001$ & 1.080 & 0.045 \\
\hline Health insurance coverage & 0.817 & 0.044 & 0.871 & 0.214 \\
\hline
\end{tabular}

Pregnancy characteristics

Gestational age at delivery (weeks)

$0.631<0.001$

Preceding birth interval $\leq 1$ year

Substance abuse

Wanted child

Child characteristics

Product of a Multiple pregnancy

Sex

$1.214 \quad 0.690$

$0.841 \quad 0.089$

$0.970 \quad 0.412$

$9.722<0.001$

$1.402<0.001$

Mother characteristics

Age

Education

Employment

Marital Status: Never married

Marital Status: Currently married

Marital Status: Previously married

Height (cm)

BMI: Low

BMI: Regular

BMI: High

Total children ever born

Previously terminated pregnancy

History of sexual abuse

History of psychological abuse

History of physical abuse

Final say

Context characteristics

Number of household members

Wealth index

Urban residency

Migration

Household head: Woman

Household head: Partner

Household head: Other

Sanitation

-2 Log likelihood
1.0110 .157

$0.962 \quad 0.002$

1.0630 .421

$0.932 \quad 0.601$

Reference

0.8710 .179

$0.995<0.001$

$1.645<0.001$

Reference

$0.886 \quad 0.226$

$0.893 \quad 0.002$

$0.962 \quad 0.635$

1.1520 .009

0.9710 .684

$0.985 \quad 0.857$

$0.975 \quad 0.427$

$0.996 \quad 0.865$

$0.979 \quad 0.645$

$0.971 \quad 0.761$

$1.151 \quad 0.258$

$1.249 \quad 0.051$

Reference

1.3280 .024

$0.915 \quad 0.423$

2185.23
Table 2 Binomial logistic regressions of LBW on prenatal care variables (Continued)

\begin{tabular}{lll}
\hline Cox \& Snell R Square & 0.01 & 0.21 \\
Nagelkerke R Square & 0.02 & 0.44 \\
\hline OR: odds ratio; Sig.: significance. & &
\end{tabular}

delivery (weeks of gestational age at delivery), [23] product of a multiple pregnancy, $[24,25]$ female newborn, [26-28] low education of the mother, [29] maternal low height and BMI, [30] and history of sexual abuse [31].

Although this study offers some advantages such as the large sample size and quality of data, it also has important limitations. First, there are many no measured confounders such as genetics, maternal history of disease and pregnancy, among others. Second, it is based on maternal information; hence, it is subject to recall bias. Third, the available data limited the possibility to study details of the antenatal care characteristics. Fourth, approximately a third of the sample was lost because the birth weight data was missing or it was not accurately recalled. Nevertheless, after performing a sensitivity analysis the results remained very similar to those originally reported in this study, so there is no reason to believe that the sample may change the results in any particular direction. Fifth, its cross-sectional design does not allow to infer causality, although there are not reasons to believe that there are temporal ambiguities, and finally, the large sample size contributes to an over-power analysis that could detect minimal effect sizes, and these effect sizes could be the result from slight biases in the sampling process.

\section{Conclusion}

A complete prenatal care, beginning as early as possible and including a good number of prenatal visits, appears to be of great importance to decrease LBW, and to avoid future associated complications. . On the other hand, the provision of care by a physician does not seem to be necessary to decrease LBW, as long as another health professional provides the prenatal care.

\section{Abbreviations}

LBW: Low birth weight; DHS: Demographic and health survey; WHO: World health organization; IUGR: Intrauterine growth restriction; MDG: Millennium development goals; BMI: Body mass index.

\section{Competing interests}

The authors declare that they have no competing interests.

\section{Author's contribution}

AMPR, VG, JA and AHM contributed to the conception and design of the study. AMPR, VG and JA collected the data. AMPR, AHM, HMN and PA contributed to the analysis and interpretation of the data. AMPR, JA, PA, HMN and AHM contributed to the drafting and revising of the manuscript. All of the authors have given final approval of the final version to be published; and agreed to be accountable for all aspects of the work in ensuring that questions related to the accuracy or integrity of any part of the work are appropriately investigated and resolved. 


\section{Acknowledgements}

The authors would like to give thanks all the members of Universidad del Rosario's public health department and its child health research line for their collaboration on the statistic analysis and valuable observations on the designing and drafting of this paper. All the funding required to develop this paper was secured from our department. We would also like to thank Macro International and the DHS program for providing the data to conduct this research.

\section{Received: 8 October 2014 Accepted: 24 April 2015}

\section{Published online: 20 May 2015}

\section{References}

1. World Health Organization WHO. Guidelines on Optimal feeding of low birthweight infants in low-and middle-income countries. In. Geneva: World Health Organization; 2011.

2. World Health Organization WHO. Public health aspects of low birth weight In: Third Report of the Expert Committee on Maternal and Child Health. Geneva: WHO; 1961

3. Quiroga, F. Protocolo de Vigilancia en Salud Pública. Bajo Peso al Nacer a Término. Instituto Nacional de Salud de Colombia. In: http://www.ins.gov.co/ lineas-de-accion/Subdireccion-Vigilancia/sivigila/Protocolos\%20SIVIGILA/ PRO\%20Bajo\%20Peso\%20al\%20Nacer\%20a\%20Termino.pdf. Accessed: 20 May 2014

4. The UN Millennium Development Goals. In: http://www.un.org/ millenniumgoals/childhealth.shtml. Accessed 20 May 2014.

5. Lawn JE, Wilczynska-Ketende K, Cousens SN. Estimating the causes of 4 million neonatal deaths in the year 2000. Int J Epidemiol. 2006;35:706-18.

6. The Million Death Study Collaborators. Causes of neonatal and child mortality in India: nationally representative mortality survey. Lancet. 2010;376:1853-60.

7. Cuevas KD, Silver DR, Brooten D, Youngblut JM, Bobo CM. The cost of prematurity: hospital charges at birth and frequency of rehospitalizations and acute care visits over the first year of life: a comparison by gestational age and birth weight. Am J Nurs. 2005;105:56-64.

8. Unicef. Estadisticas Colombia. New York. Available from: http://www.unicef.org/ spanish/infobycountry/colombia_statistics.html. Accessed May 21, 2014

9. Moos MK. Prenatal care: limitations and opportunities. J Obstet Gynecol Neonatal Nurs. 2006:35:278-85.

10. Alexander GR, Kotelchuck M. Assessing the role and effectiveness of prenatal care: history, challenges, and directions for future research. Public Health Rep. 2001;116:306-16.

11. WHO Regional Office for Europe's Health Evidence Network. What is the effectiveness of antenatal care? Geneva: World Health Organization WHO; 2005.

12. UNICEF. UNICEF Data. Monitoring the Situation of Children and Women. Only half of women worldwide receive the recommended amount of care during pregnancy. In: http://www.data.unicef.org/maternal-health/antenatal-care. Accessed March 26, 2015.

13. Profamilia. Encuesta Nacional de Demografia y Salud. Bogota: Profamilia; 2011.

14. Así vamos en salud. Prevalencia de Bajo peso al nacer en Colombia. In: http://www.asivamosensalud.org/inidicadores/estado-de-salud/grafica.ver/ 14. Accessed May 2, 2014.

15. DANE. Estadísticas Vitales. Departamento Administrativo Nacional de Estadística. In: http://www.dane.gov.co/index.php/esp/poblacion-y-registros-vitales/ nacimientos-y-defunciones/nacimientos-y-defunciones/118-demograficas/ estadisticas-vitales/2882-nacimientos-2009-preliminar. Accessed: 30 May 2014

16. Valero De Bernabe J. Risk factors for low birth weight: a review. Eur J Obstet Gynecol Reprod Biol. 2004;116:3-15.

17. Coutinho PR, Cecatti JG, Surita FG, Souza JP, Morais SS. Factors associated with low birth weight in a historical series of deliveries in Campinas. Brazil Rev Assoc Med Bras. 2009:55:692-9.

18. Letamo G, Majelantle RG. Factors influencing low birth weight and prematurity in Botswana. J Biosoc Sci. 2001;33(3):391-403.

19. Metcalfe A, Grabowska K, Weller C, Tough SC. Impact of prenatal care provider on the use of ancillary health services during pregnancy. BMC Pregnancy Childbirth. 2013;11:13-62.

20. Jackson DL, Jackson DJ, Lang JM, Swartz WH, Ganiats TG, Fullerton J, et al. Outcomes, safety, and resource utilization in a collaborative care birth center program compared with traditional physician-based perinatal care. Am J Public Health. 2003;93:999-1006.
21. Rani M, Bonu S, Harvey S. Differentials in the quality of antenatal care in India. Int J Qual Health Care. 2008;20:62-71.

22. WHO Global health observatory. Antenatal care - At least 4 visits. Geneva; 2014. In: http://www.who.int/gho/urban_health/services/antenatal_care_ text/en/. Accessed June 2, 2014

23. Halbreich $U$. The association between pregnancy processes, preterm delivery, low birth weight, and postpartum depressions-The need for interdisciplinary integration. Am J Obstet Gynecol. 2005;193:1312-22.

24. McDonald SD, Han Z, Mulla S, Ohlsson A, Beyene J, Murphy KE, et al. Preterm birth and low birth weight among in vitro fertilization twins: a systematic review and meta-analyses. Eur J Obstet Gynecol Reprod Biol. 2010;148:105-13.

25. Sezer SD, Küçük M, Yüksel H, Odabaşi AR, Türkmen $M$, Cakmak BÇ, et al. Perinatal and neonatal outcomes of twin pregnancies in Turkey. Twin Res Hum Genet. 2011;14:201-12.

26. Halileh S, Abu-Rmeileh N, Watt G, Spencer N, Gordon N. Determinants of birthweight: gender based analysis. Matern Child Health J. 2008:12:606-12.

27. Tamimi RM, Tamimi RM, Lagiou P, Mucci LA, Hsieh CC, Adami HO, et al. Average energy intake among pregnant women carrying a boy compared with a girl. BMJ. 2003;326:1245-6.

28. Al-Qutob R, Mawajdeh S, Allosh R, Mehayer H, Majali S. The effect of prenatal knowledge of fetal sex on birth weight: a study from Jordan. Health Care Women Int. 2004;25:281-91.

29. Gavin AR, Thompson E, Rue T, Guo Y. Maternal early life risk factors for offspring birth weight: findings from the add health study. Prev Sci. 2012;13:162-72.

30. Shaw GM, Wise PH, Mayo J, Carmichael SL, Ley C, Lyell DJ, et al. March of Dimes Prematurity Research Center at Stanford University School of Medicine. Maternal prepregnancy body mass index and risk of spontaneous preterm birth. Paediatr Perinat Epidemiol. 2014;28:302-11.

31. Grimstad H, Schei B. Pregnancy and delivery for women with a history of child sexual abuse. Child Abuse Negl. 1999;23:81-90.

\section{Submit your next manuscript to BioMed Central and take full advantage of:}

- Convenient online submission

- Thorough peer review

- No space constraints or color figure charges

- Immediate publication on acceptance

- Inclusion in PubMed, CAS, Scopus and Google Scholar

- Research which is freely available for redistribution 